\title{
The relationship between serum levels of lipid profile and activity of rheumatoid arthritis
}

\author{
Sohair M. Mahrous, Abdullah M. A. Radwan, Osama S. Daifallah and Sherif A. \\ Sayed \\ Department of Rheumatology and Rehabilitation, Sohag Faculty of Medicine, Sohag \\ University
}

\section{Abstract}

Introduction: Rheumatoid arthritis (RA) is a chronic inflammatory disease of unknown etiology marked by a symmetric, peripheral polyarthritis. It is the most common form of chronic inflammatory arthritis and often results in joint damage and physical disability. As it is a systemic disease, it may result in variety of extra-articular manifestations, including fatigue, subcutaneous nodules, lung involvement, pericarditis, peripheral neuropathy, vasculitis, and hematologic abnormalities.

Aim of the work: Show changes of serum lipid profile in patients with rheumatoid arthritis.

Patients and Methods: Fifty patients with rheumatoid arthritis who diagnosed according to (EULAR/ ACR2010) criteria for rheumatoid arthritis, 47 females and 3 males with a mean age of $36.80 \pm 6.03$ years. Fifty control healthy subjects included 43 females and 7 males with a mean age of $36.14 \pm 7.73$ years were examined for their lipid profile parameters and disease activity. Lipid profile parameters (total cholesterol, high-density lipoprotein cholesterol, lowdensity lipoprotein cholesterol and atherogenic index ratio), erythrocyte sedimentation rate and C-reactive protein; all were determined for both the patients and control groups.

Results: The results of the present study revealed that rheumatoid arthritis patients exhibited a highly significant increase in total cholesterol and low-density lipoprotein cholesterol $(\mathrm{p}=0.0001)$, with a significant increase in high-density lipoprotein cholesterol $(\mathrm{p}=0.002)$. As a consequence, the atherogenic index ratio was significantly higher $(p=0.0001)$. The rheumatoid factor, CRP and ESR were higher in patients with RA than in control group with very highly significant difference $(\mathrm{p}=0.0001)$. There is a significant correlation between disease activity score (DAS 28) and different parameters of lipid profile which was a highly significant with LDL and TC/HDL (0.9-0.8) respectively and was less significant with other parameters. The disease duration for rheumatoid arthritis patients was significantly correlated with Das 28 score ( $\mathrm{p}=0.01)$.

Conclusion: Rheumatoid arthritis patients are characterized by an atherogenic lipid profile in comparison with the healthy controls. Recognition and treatment of early rheumatoid arthritis and reduction of cardiac risk factor has greater impact on the course of the disease.

Key words: Lipid profile, rheumatoid arthritis.

\section{Introduction}

Rheumatoid arthritis (RA) is a chronic inflammatory disease of unknown etiology marked by a symmetric, peripheral polyarthritis. It is the most common form of chronic inflammatory arthritis and often results in joint damage and physical disability. As it is a systemic disease, it may result in variety of extra-articular manifestations, including fatigue, subcutaneous nodules, lung involvement, pericarditis, peripheral neuropathy, vasculitis, and hematologic abnormalities ${ }^{(\mathbf{1})}$.

Patients with Rheumatoid arthritis (RA) have high mortality rate when compared to the general population, with cardiovascular disease (CVD) contributing up to $50 \%$ of all deaths, furthermore, it was found that the increased mortality is predominantly due to accelerated coronary artery disease and cerebrovascular atherosclerosis. An increased 
prevalence of atherosclerosis in RA may be suspected for several reasons: atherogenic side effects of some antirheumatic medications, the effects of chronic systemic inflammation on the vascular endothelium or shared mechanisms between RA and atherosclerosis ${ }^{(\mathbf{1})}$.

Systemic inflammation may contribute to CVD risk, either directly or indirectly through an array of mechanisms, from its effect on endothelial function to its effect on the lipid profile. Activation of the acute phase response, via inflammation or infection alters the lipid profile ${ }^{(2)}$.

Cardiovascular disease in RA may result from accelerated atherosclerosis caused by clinical or subclinical vasculitis. The main determinants of cardiovascular risk in the general population are the concentrations of serum low density lipoprotein (LDL) and high density lipoprotein (HDL) cholesterol. Oxidative modification of LDL may also be important and it is of interest that oxidized LDL has been noted in RA synovial biopsy specimens. Products of LDL oxidation may be recognized by the scavenger receptor leading to increased uptake of the modified lipoprotein particle by macrophages, they may be directly cytotoxic to endothelial cells, chemotactic for inflammatory cells, and cause functional changes in smooth muscle. The inflammatory environment and disturbed antioxidant mechanisms in RA may promote LDL oxidation, thereby facilitating atherogenesis at lower ambient lipid concentrations and placing RA patients at higher cardiovascular risk ${ }^{(3)}$.

Previous report said that the lipid profile of patients with active or untreated RA is primarily characterized by a decrease in serum levels of HDL$\mathrm{C}$ where as contrasting result have been published on the serum levels of TC and LDL-C importantly, the reduction in HDL-C has as a consequence the increase in the TC/HDL-C ratio so called Atherogenic Index (AI), which is an important prognostic marker for cardiovascular disease indeed the risk of myocardial infarction increases considerably when this ratio is higher than 5 and it should ideally be 4 or less ${ }^{(4)}$.

\section{Aim of the work:}

Show changes of serum lipid profile in patients with rheumatoid arthritis relative to disease activity and to look for any correlation between lipid profile parameters and different inflammatory markers.

\section{Patients and Methods:}

Design: Case control observational study.

\section{Patients:}

100 persons and divided into:

1. Case group:

- 50 patients with established rheumatoid arthritis diagnosed according to (EULAR/ ACR 2010) for RA ${ }^{(5)}$

- Patient recruited from Rheumatology and Rehabilitation Outpatient Clinic in Sohag University Hospital in the period between January 2016 to June 2016.

2. Control group:

- 50 apparently healthy volunteer were included. They are randomly selected from the officers working in Sohag University Hospital with considering age and sex matched to the case group.

\section{Methods:}

Following history taking, complete general and musculoskeletal examination of RA patients will be conducted. Then, RA patients will be subjected to the following assessment tools:

1. Demographic data: name, age, sex, job, marital state, education, disease duration and morning stiffness will be recorded for every RA patient. 
2. Rheumatoid arthritis medications.

3. Height $(\mathrm{cm})$.

4. Weight $(\mathrm{Kg})$.

5. Body mass index (BMI).

6. Rheumatoid factor (RF): Serum RF concentrations will be determined by immuno-nephelometry method on Turbox nephelometer (Orion diagnostica, Finland). The concentrations will be expressed as $\mathrm{IU} / \mathrm{ml}$ for RF. RF concentration $\geq$ $25 \mathrm{IU} / \mathrm{ml}$ will be considered positive for RF.

7. C-reactive protein.

8. Erythrocyte Sedimentation Rate (ESR)

9. Anti-citrullinated protein antibody (ACPAs)

10. Visual Analogue Scale of pain (VAS).

11. Disease Activity Score-28 (DAS28).

12. Lipid profile parameters:

a. TC $(\mathrm{mmol} / \mathrm{L})$.

b. $\operatorname{LDL}(\mathrm{mmol} / \mathrm{L})$.

c. $\mathrm{HDL}(\mathrm{mmol} / \mathrm{L})$.

d. $\mathrm{TG}(\mathrm{mmol} / \mathrm{L})$.

e. $\operatorname{VLDL}(\mathrm{mmol} / \mathrm{L})$.

f. TC/HDL (Atherogenic ratio).

\section{Samples:}

\section{Blood Samples:}

Blood samples were taken from every case as follow:

B $6 \mathrm{ml}$ venous blood was collected by clean venipuncture. Each sample was divided into 2 portions:

B $3 \mathrm{ml}$ on K EDTA (Thylene Diamine tetra Acetic Acid) for $\mathrm{CBC}$ and ESR.

B $3 \mathrm{ml}$ on plain tube for separation of serum, which is divided into aliquots, either used immediately (for routine investigations) or kept frozen at -70 until used for (RF).

1. ESR: is widely used laboratory measure of disease activity in clinical medicine. It indirectly reflects the potentially increased concentrations of serum proteins.
2. CRP: is the acute-phase protein that has been most widely assessed. It can be measured quantitatively with immunoassays that are both simple and rapid to perform .It has mostly been evaluated for short-term outcome of RA.

3. RF: an antibody directed against the $\mathrm{Fc}$ fragment of $\mathrm{IgG}$, is present in the sera of more than $75 \%$ of patient.

4. Lipid profile: Patient should be on a stable diet for 3 weeks, and fast 912 hours before collection, $1.5 \mathrm{~mL}$ (Minimum: $0.6 \mathrm{~mL}$ ) blood Routine blood collection.

5. Anti CCP: are autoantibodies that are directed against peptides and proteins that are citrullinated. They are present in the majority of patients with rheumatoid arthritis. Clinically, cyclic citrullinated peptides (CCP) are frequently used to detect these antibodies ${ }^{(6)}$.

Note: Venipuncture should occur prior to administration of $\mathrm{N}$ acetylcysteine (NAC) or metamizole due to the potential for falsely depressed results.

\section{Assessment of disease activity:}

To calculate the DAS28 the rheumatologist will:

1. Count the number of swollen joints (out of the 28 joints of the hands, wrists, elbows, shoulders, and knees),

2. Count the number of tender joints (out of the 28),

3. Take blood to measure the erythrocyte sedimentation rate (ESR) or $\mathrm{C}$ reactive protein (CRP),

4. Ask the patient to make a 'global assessment of health 'on visual analog scale (VAS) (indicated by marking a $10 \mathrm{~cm}$ line between very good and very bad) and calculated in DAS28 $=056 \mathrm{~V}$ (TEN28)+0 28V (SW28) +0 70 Ln (ESR)-/-0.014 (GH) 
The results are combined to produce the DAS28 score, which correlates with the extent of disease activity:

B2.2-2.6: Disease remission.

ß2.6 - 3.2: Low disease activity.

ß3.2- 5.1: Moderate disease activity.

ß>5.1: High disease activity.

\section{Inclusion criteria:}

(1) Age 18-45 years

(2) Able and willing to give written informed consent and comply with the requirements of the study protocol.

(3) Patients with RA diagnosed according to (EULAR/ ACR 2010).

\section{Exclusion criteria:}

\section{Results}

There is no significant difference found in height, weight and body mass index between cases and controls. The rheumatoid factor, CRP and ESR were higher in patients with RA than in control group with very highly significant difference $(\mathrm{p}=0.0001)$. There were different groups of drug combination used by our patients. The disease duration for rheumatoid arthritis patients was $6.38 \pm 5.63$ ranging between 3 months-20 years. The mean disease activity score (DAS 28) for rheumatoid arthritis patients were $5.16 \pm 0.90$ with a range of $2.63-6.81$. With a significant correlation 0.01 as shown in table 1 .

Total cholesterol, LDL and VLDL were highly significantly higher in patients with RA ( $p=0.0001)$. HDL was significantly higher in the RA patients than with control patients a significant difference $(p=0.002)$. Regarding total cholesterol and HDL-C the mean atherogenic ratio of TC /HDL-C was higher in patients with RA than in control group with very highly significant difference $(p=0.0001)$. Triglyceride was significantly higher in patients with RA than control group $(p=0.002)$ as shown in table 2.

There is a significant correlation between disease activity score (DAS 28) and different parameters of lipid profile which was a highly significant with LDL and TC/HDL (0.9-0.8) respectively and was less significant with other parameters.

Table 1. The relation between disease duration(DD) and (DAS-28) score(Das)

\begin{tabular}{rlrr}
\hline & & DD & Das \\
DD & Pearson Correlation & 1 & .518 \\
& Sig. (1-tailed) & & .000 \\
Nas & 50 & 50 \\
& Pearson Correlation & .518 & 1 \\
& Sig. (1-tailed) & .000 & 50
\end{tabular}

Correlation is significant at the 0.01 level (1-tailed). 
Table 2. Lipid profiles of studied populations

\begin{tabular}{|c|c|c|c|c|}
\hline \multicolumn{2}{|l|}{ Variables } & $\begin{array}{c}\text { Rheumatoid } \\
\text { arthritis } N=50\end{array}$ & $\begin{array}{c}\text { Controls } \\
\mathrm{N}=50\end{array}$ & p-value \\
\hline \multirow[t]{2}{*}{$\begin{array}{l}\text { Total cholesterol } \\
(\mathrm{mmol} / \mathrm{L})\end{array}$} & $\begin{array}{c}\text { Mean } \pm \\
\text { SD }\end{array}$ & $201.48 \pm 31.50$ & $144.56 \pm 32.07$ & $<0.0001$ \\
\hline & $\begin{array}{l}\text { Median } \\
\text { (range) }\end{array}$ & $210(130-273.8)$ & $150(80-190)$ & \\
\hline \multirow[t]{2}{*}{$\begin{array}{c}\text { Triglyceride } \\
(\mathbf{m m o l} / \mathrm{L})\end{array}$} & $\begin{array}{c}\text { Mean } \pm \\
\text { SD }\end{array}$ & $128.59 \pm 52.13$ & $100.34 \pm 36.18$ & 0.002 \\
\hline & $\begin{array}{l}\text { Median } \\
\text { (range) }\end{array}$ & $116.5(41-315)$ & 96.5 (47-198) & \\
\hline \multirow[t]{2}{*}{ LDL (mmol/L) } & $\begin{array}{c}\text { Mean } \pm \\
\text { SD }\end{array}$ & $107.05 \pm 33.66$ & $83.56 \pm 22.70$ & 0.0001 \\
\hline & $\begin{array}{l}\text { Median } \\
\text { (range) }\end{array}$ & $106.2(28.3-218.3)$ & $88.5(16-124)$ & \\
\hline \multirow[t]{2}{*}{ HDL (mmol/L) } & $\begin{array}{c}\text { Mean } \pm \\
\text { SD }\end{array}$ & $46.21 \pm 7.19$ & $40.62 \pm 9.93$ & 0.002 \\
\hline & $\begin{array}{l}\text { Median } \\
\text { (range) }\end{array}$ & $45(27-64)$ & $40(22-64)$ & \\
\hline \multirow[t]{2}{*}{ VLDL (mmol/L) } & $\begin{array}{c}\text { Mean } \pm \\
\text { SD }\end{array}$ & $27.15 \pm 10.09$ & $20.06 \pm 7.24$ & 0.0001 \\
\hline & $\begin{array}{l}\text { Median } \\
\text { (range) }\end{array}$ & $29(8.2-63)$ & $19(9-40)$ & \\
\hline \multirow[t]{2}{*}{$\begin{array}{l}\text { Atherogenic ratio } \\
\text { (TC/HDL) }\end{array}$} & $\begin{array}{c}\text { Mean } \pm \\
\text { SD }\end{array}$ & $4.47 \pm 1.02$ & $3.64 \pm 0.72$ & $<0.0001$ \\
\hline & $\begin{array}{l}\text { Median } \\
\text { (range) }\end{array}$ & $4.51(2.17-7.75)$ & $\begin{array}{c}3.59(2.15- \\
5.38)\end{array}$ & \\
\hline
\end{tabular}

\section{Discussion}

Several pieces of evidence indicate that rheumatoid arthritis (RA) is a proatherogenic disease associated with increased cardiovascular (CV) mortality. C-reactive protein and ESR are acute phase reactants for RA which increase in active disease may contribute to atherosclerosis because it stimulates macrophage to produce tissue factor, a procoagulant that is found in atherosclerotic plaque and significantly associated with risk of CVD in RA ${ }^{(7)}$. Besides genetic and traditional $\mathrm{CV}$ risk factors, chronic inflammation has emerged as a pivotal component implicated in the development of this process. A chronic inflammatory burden, determined by the mean values of $\mathrm{C}$-reactive protein (CRP) over the extended follow-up of patients with RA, was associated with subclinical atherosclerosis and increased risk of $\mathrm{CV}$ events. In keeping with these observations, in a large retrospective cohort study, $\mathrm{CV}$ diseaserelated mortality was increased in RA patients with elevated measures of inflammation markers. These findings are in accordance with data from the general population that showed that CRP could be an independent predictor of $\mathrm{CV}$ disease with $\mathrm{CRP}$ values $\geq 3$ $\mathrm{mg} / \mathrm{L}$ defining high CV-risk individuals. With respect to this, levels of the proinflammatory cytokine interleukin-6, the main inducer of CRP, also predict outcome following hospitalisation for unstable angina ${ }^{(8)}$. 
In our study there is no age and gender differences were found between RA patients and their controls with 47 females (94\%) and 3 males (6\%). Fifty control healthy subjects included 43 females (86\%) and 7 males (14\%). The reasons for this overrepresentation of women are not clear, but genetic (Xlinked) factors and hormonal aspects are likely to be involved ${ }^{(8)}$. The age of our patients range from 23 to 45 years with a mean age of $36.8 \pm 6.03$ years, with joint deformations more in younger patients, but with lower disease activity than older patients. These findings agreed with Makinodan and Kay., ${ }^{(9)}$ who found that the difference in the clinical presentation could be explained partly by altered immune responses in elderly patients. Indeed, the aging process is associated with a decreased proliferation of $\mathrm{T}$ cells. Also there is no significant difference found in height, weight and body mass index between cases and controls with $(\mathrm{p}=0.59)$. The relation between BMI and activity of the disease depends on the disease duration, patients with early RA, of up to 3-years duration have a protective role of higher BMI against joint damage ${ }^{(\mathbf{1 0})}$.

However, it must be noted that BMI was no longer associated with disease activity or separately with its components in patients with disease duration of more than 2 years. This finding indicates that the possible protective effects of obesity in early RA may be diminished later in the course of the disease ${ }^{(10)}$. The Rheumatoid factor, CRP and ESR were higher in patients with RA than in control group with very highly significant difference $\quad(p=0.0001)$ which agree with Van Zeben et al., ${ }^{(11)}$ who found that the frequency of RF was greater in RA patients with high disease activity versus patients with low and moderate disease activity with strong relationship between RF and activity of the disease.

In our study there was a significant correlation between disease duration and disease activity score (DAS-28) $(p=0.01)$ that leads to alteration of parameters of lipid profiles of the patients and increase the risk of cardiovascular diseases among patients of RA. This study is consistent with another study reported by Arts et al., (12). In our study there was a hypercholestermia which is an important factor in development of atherosclerosis also there was increase in HDL cholesterol which has atheroprotective function by preventing LDL cholesterol oxidation and this study is consistent with another study reported by Toms et al., (2) who found that dyslipidaemia can manifest in RA patients with both early and advanced disease.

Another substantial finding was presence of significant increase of LDL-cholesterol in RA patient with activiy. Thus these altered lipoproteins along with an increase in lipid peroxidation products suggest that RA patients are at a high risk for the development of coronary heart disease. This conclusion is in agreement with reports from Nurmohamed et al., (13), who showed significant increase in LDL level and might be due to increased levels of secretory group IIa phospholipase A2, an acute phase protein and an independent cardiovascular risk factor. Low density lipoprotein is associated with the risk of coronary heart disease and also has been shown to undergo oxidation forming oxidized LDL, which leads to phospholipid release, activating endothelial cells, thereby initiating an inflammatory process which leads to the formation of foam cells and subsequent fatty streaks. Under normal condition HDL exerts its 
antiatherogenic role by protecting LDL from oxidation ${ }^{(\mathbf{1 4})}$.

In this study there was significant increase of TG and VLDL in RA patients with activity, which differ from another study performed by Suresh et al., (14) which reported decrease in TG level during activity.

In our study the atherogenic index showed highly significant increase in RA patients than control group $(p=0.0001)$ with growing evidence that ratios of lipid components have a higher predictive value of first myocardial infarction than individual components of the lipid profile and our results are similar to others which found that lipid ratio highly significant increase in RA patients when

\section{Conclusion:}

Patients with RA were characterized by an atherogenic lipid profiles during activity. Thus, early immuno-intervention to control disease activity may reduce the risk of the atherosclerotic process and cardiovascular events in RA patients.

\section{References:}

1. Kaplan MJ. Cardiovascular disease in rheumatoid arthritis. Current opinion in rheumatology. 2006;18(3):289-97.

2. Toms TE, Panoulas VF, Douglas KM, Nightingale P, Smith JP, Griffiths H, et al. Are lipid ratios less susceptible to change with systemic inflammation than individual lipid components in patients with rheumatoid arthritis? Angiology. 2011;62(2):167-75.

3. Nakken B, Szodoray P. Accelerated atherosclerosis in rheumatoid arthritis: rationale for mannose-binding lectins? The Journal of rheumatology. 2010;37(3):482-4.

4. Georgiadis AN, Papavasiliou EC, Lourida ES, Alamanos Y, Kostara $\mathrm{C}$, Tselepis $\mathrm{AD}$, et al. Atherogenic compared with controls as lipid ratio have been considered a more reliable way of assessing the lipid profile by overcoming individual fluctuations in lipids occurring as part of disease flares ${ }^{(2)}$.

The present study showed that RA patients during activity exhibited high TC and HDL serum levels. The increment in TC and HDL was directly correlated with the increment of CRP level and ESR values, this result is consistent with other study done by Peters et al., (15) who suggested that the correlation between TC and ESR and CRP in active RA patients raises the possibility that cholesterol behave like an activity marker.

lipid profile is a feature characteristic of patients with early rheumatoid arthritis: effect of early treatment--a prospective, controlled study. Arthritis research \& therapy. 2006;8(3):R82.

5. Aletaha D, Neogi $T$, Silman AJ, Funovits J, Felson DT, Bingham CO, 3rd, et al. 2010 Rheumatoid arthritis classification criteria: an American College of Rheumatology/European League Against Rheumatism collaborative initiative. Arthritis and rheumatism. 2010;62(9):2569-81.

6. Puszczewicz M, Iwaszkiewicz C. Role of anti-citrullinated protein antibodies in diagnosis and prognosis of rheumatoid arthritis. Archives of medical science : AMS. 2011;7(2):189-94.

7. Myasoedova E, Crowson CS, Kremers HM, Roger VL, Fitz-Gibbon PD, Therneau TM, et al. Lipid paradox in rheumatoid arthritis: the impact of serum lipid measures and systemic inflammation on the risk of cardiovascular disease. Annals of the rheumatic diseases. 2011;70(3):482-7. 
8. Lakatos J, Harsagyi A. Serum total, HDL, LDL cholesterol, and triglyceride levels in patients with rheumatoid arthritis. Clinical biochemistry. 1988;21(2):93-6.

9. Makinodan T, Kay MM. Age influence on the immune system. Advances in immunology. 1980;29:287-330.

10. Westhoff G, Rau R, Zink A. Radiographic joint damage in early rheumatoid arthritis is highly dependent on body mass index. Arthritis and rheumatism. 2007;56(11):3575-82.

11. van Zeben D, Hazes JM, Zwinderman $\mathrm{AH}$, Cats $\mathrm{A}$, van der Voort EA, Breedveld FC. Clinical significance of rheumatoid factors in early rheumatoid arthritis: results of a follow up study. Annals of the rheumatic diseases. 1992;51(9):102935 .

12. Arts EE, Popa CD, Smith JP, Arntz OJ, van de Loo FA, Donders R, et al. Serum samples that have been stored long-term ( $>10$ years) can be used as a suitable data source for developing cardiovascular risk prediction models in large observational rheumatoid arthritis cohorts. BioMed research international. 2014;2014:930925.

13. Nurmohamed MT. Atherogenic lipid profiles and its management in patients with rheumatoid arthritis. Vascular health and risk management. 2007;3(6):845-52.

14. Vijayakumar D, Suresh K, Manoharan S. Altered pattern of lipids in plasma and erythrocyte membranes of rheumatoid arthritis patients. Indian journal of clinical biochemistry : IJCB. 2005;20(1):52-5.

15. Peters MJ, Symmons DP, McCarey D, Dijkmans BA, Nicola P, Kvien TK, et al. EULAR evidencebased recommendations for cardiovascular risk management in patients with rheumatoid arthritis and other forms of inflammatory arthritis. Annals of the rheumatic diseases. 2010;69(2):325-31. 